\title{
High Proton Conductivity of Zinc Oxalate Coordination Polymers Mediated by a Hydrogen Bond with Pyridinium
}

\author{
Teppei Yamada*, ${ }^{\dagger}, \ldots, \mathbb{I}$, Takuya Nankawa*,$\S$ \\ 'Division of Chemistry and Biochemistry, Faculty of Engineering, Kyushu University, Motooka 744, Nishi-ku, Fukuoka 819-0395, Japan \\ *enter for Molecular Systems, Kyushu University, Motooka 744, Nishi-ku, Fukuoka 819-0395, Japan \\ IJST-PRESTO, 4-1-8 Honcho, Kawaguchi, Saitama 332-0012, Japan
}

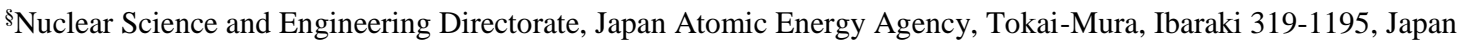

\section{Synthesis of $\left(\mathrm{C}_{5} \mathrm{H}_{6} \mathrm{~N}\right)_{2}\left[\mathrm{Zn}_{2}(\mathrm{ox})_{3}\right] \cdot \mathrm{H}_{2} \mathrm{O}$}

Oxalic acid dimethyl ester $(1.04 \mathrm{~g}, 8.8 \mathrm{mmol})$, pyridine $(880 \mathrm{mg}, 11.3 \mathrm{mmol})$, zinc oxide $(272 \mathrm{mg}, 3.36 \mathrm{mmol})$ and $2 \mathrm{~mL}$ of water are put into a Teflon-lined stainless steel autoclave and warmed at $110{ }^{\circ} \mathrm{C}$ for 24 hours. The samples are filtrated, washed several times with water and air dried. Yield: 609. mg (30.7\%). Elemental analysis calcd (found)\% for $\left(\mathrm{C}_{5} \mathrm{H}_{6} \mathrm{~N}\right)_{2}\left[\mathrm{Zn}_{2}(\mathrm{ox})_{3}\right] \cdot 1 \mathrm{H}_{2} \mathrm{O}: \mathrm{C} 33.53(33.61), \mathrm{H} 2.46$ (2.82), N 4.89 (4.56).

Total reaction scheme is below:

$2 \mathrm{ZnO}+2 \mathrm{C}_{5} \mathrm{H}_{5} \mathrm{~N}+3 \mathrm{Me}_{2} \mathrm{Ox}+5 \mathrm{H}_{2} \mathrm{O} \rightarrow\left(\mathrm{C}_{5} \mathrm{H}_{6} \mathrm{~N}\right)_{2}\left[\mathrm{Zn}_{2}(\mathrm{ox})_{3}\right] \mathrm{H}_{2} \mathrm{O}+6 \mathrm{MeOH}$

\section{Physical measurements.}

X-ray powder diffraction (XRPD) measurements were carried out using Rigaku Smart Lab Diffractometer operated at $40 \mathrm{kV}$ and $35 \mathrm{~mA}$ using $\mathrm{CuK} \alpha$ radiation $(\lambda=1.54049 \AA)$.

FT-IR spectra were recorded on a Shimadzu 8400 Spectrometer equipped with ATR prism. Thermogravimetric analyses (TGA) was carried out using TG/DTA 7300 (Seiko Instruments) with heating rate of $10{ }^{\circ} \mathrm{C} / \mathrm{min}$ under $\mathrm{N}_{2}$ flow $(100 \mathrm{~mL} / \mathrm{min})$ condition. Proton conductivity was measured using the AC impedance method on a sample pellets $(\sim 0.57 \mathrm{~mm}$ in thickness $\times 3.0 \mathrm{~mm} \phi)$ compacted with handy press made (Thermo Fisher). The impedance measurement was carried out by conventional quasi-four-probe method using gold paste and gold wires with a Solartron 1260 Impedance / Gain-Phase Analyzer in the frequency range 1 to $10 \mathrm{MHz}$ under controlled temperature and humidity using SH-221 incubator (ESPEC). The samples were put under certain temperature and humidity condition for more than two hours before measuring the impedance.

Water adsorption isotherms were measured at $298 \mathrm{~K}$ with an automatic vapor adsorption apparatus, BELSORP-max (BEL Japan). Samples were thoroughly dehydrated prior to the measurement by heating at $100{ }^{\circ} \mathrm{C}$ for 12 hours under vacuum.

\section{Crystal Structure Determination.}

A single crystal of approximate dimensions of $0.05 \times 0.05 \times 0.03 \mathrm{~mm}$ was used for collecting X-ray diffraction data on a Rigaku AFC 10 diffractometer with Saturn 724 equipped with a MicroMax 007HF/ VariMax rotating anode X-ray generator with confocal monochromated MoK $\alpha$ Radiation $(\lambda=0.71073 \AA)$ at $90 \mathrm{~K}$. The crystal was mounted on a goniometer with Paraton and cryoloop.

The structure was solved by the direct method and expanded using Fourier techniques. All calculations were performed using the Yadokari-XG software package ${ }^{\mathrm{S} 1, \mathrm{~S} 2}$. First structure was found with SHELX-T program ${ }^{\mathrm{S} 3}$, and Full-matrix least squares refinements were carried out using SHELX-2014 ${ }^{\mathrm{S} 4}$ with anisotropic thermal parameters for $\left[\mathrm{Zn}_{2}(\mathrm{ox})_{3}\right]$ frameworks.

Crystal data: $\mathrm{C}_{16} \mathrm{H}_{16} \mathrm{~N}_{2} \mathrm{O}_{14} \mathrm{Zn}_{2}$, molecular weight $=591.05$, monoclinic, space group $C 2 / m$ (No. 12), $Z=2, a=9.4238(15) \AA, b=$ 16.1699(16) ̊̊, $c=7.5876(11) \AA, \beta=107.413(5)^{\circ}, V=1103.2(3) \AA^{3}, D_{\text {calcd }}=1.779 \mathrm{~g} \mathrm{~cm}^{-3}, \mu(\mathrm{MoK} \alpha)=2.249 \mathrm{~cm}^{-1}, R_{1}=2.83 \%(|I|>$ $2 \sigma(I)), w R_{2}=7.59 \%$ (all reflections). $\mathrm{GOF}=1.107$, $\max$ shift $/ \mathrm{su}=0.001$.

For the anhydrous pattern, a good crystal was selected and put on the goniometer, and was exposed to dry nitrogen gas flow at $30{ }^{\circ} \mathrm{C}$. Cell parameters were monitored, and after the cell parameters became constant, temperature of the nitrogen gas flow decreased until $130{ }^{\circ} \mathrm{C}$ and the diffraction data were collected.

Crystal data: $\mathrm{C}_{16} \mathrm{H}_{12} \mathrm{~N}_{2} \mathrm{O}_{12} \mathrm{Zn}_{2}$, molecular weight $=555.02$, monoclinic, space group $C 2 / c$ (No. 15), $Z=4, a=15.06(3) \AA, b=15.76(3)$ $\AA, c=9.879(19) \AA, \beta=117.856(17)^{\circ}, V=2073(7) \AA^{-3}, D_{\text {calcd }}=1.778 \mathrm{~g} \mathrm{~cm}^{-3}, \mu(\mathrm{MoK} \alpha)=2.381 \mathrm{~cm}^{-1}, R_{1}=11.21 \%(|I|>2 \sigma(I)), w R_{2}=$ $35.18 \%$ (all reflections). GOF $=0.971, \mathrm{max}$ shift $/ \mathrm{su}=0.000 . \mathrm{CCDC} 1030608$

S1) Yadokari-XG, Software for Crystal Structure Analyses, K. Wakita (2001);

S2) Kabuto, C.; Akine, S.: Nemoto, T.; Kwon, E., J. Cryst. Soc. Jpn., 51(3), 218-224 (2009). 


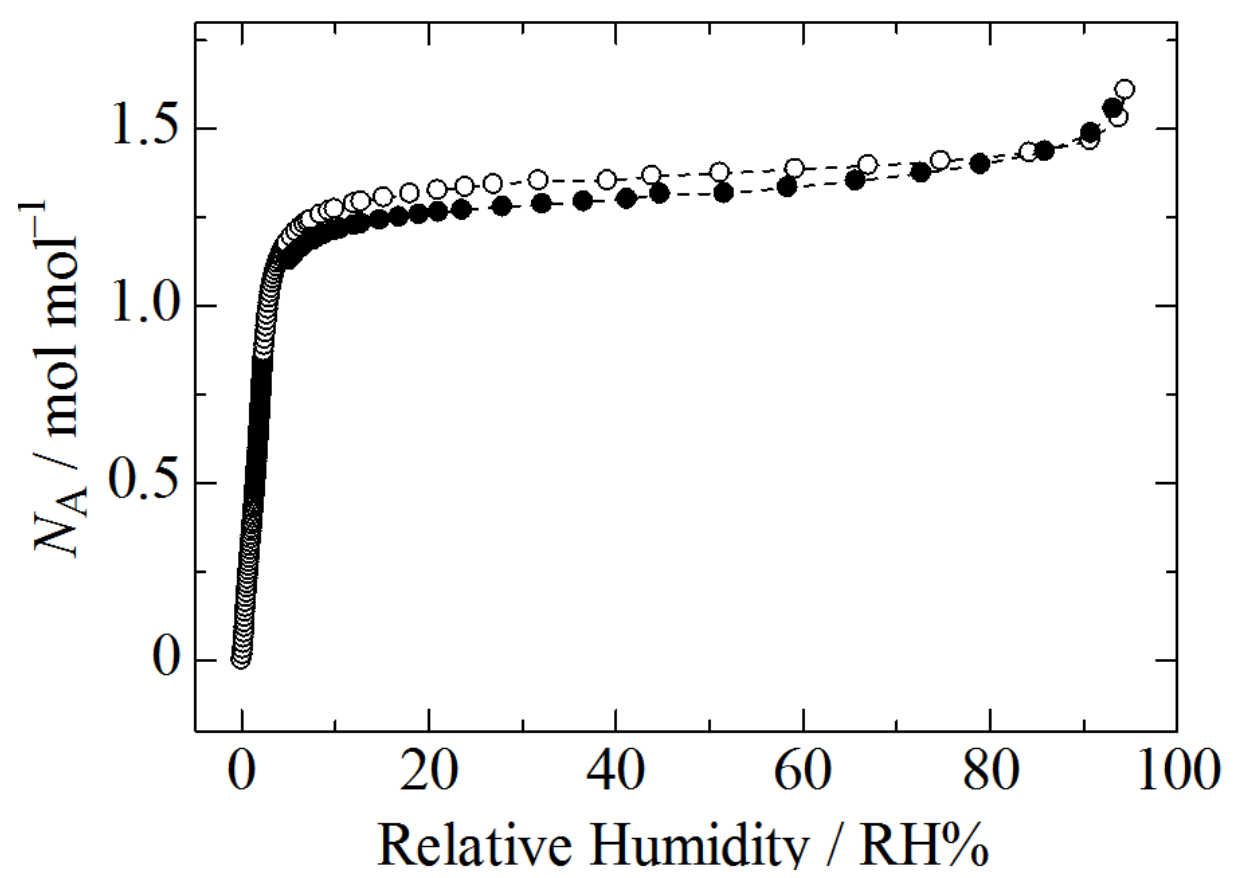

Fig. S1 Water adsorption (closed circles) and desorption (open circles) isotherms of $\left(\mathrm{C}_{5} \mathrm{H}_{6} \mathrm{~N}\right)_{2}\left[\mathrm{Zn}_{2}(\mathrm{ox})_{3}\right]$ at $298 \mathrm{~K}$.

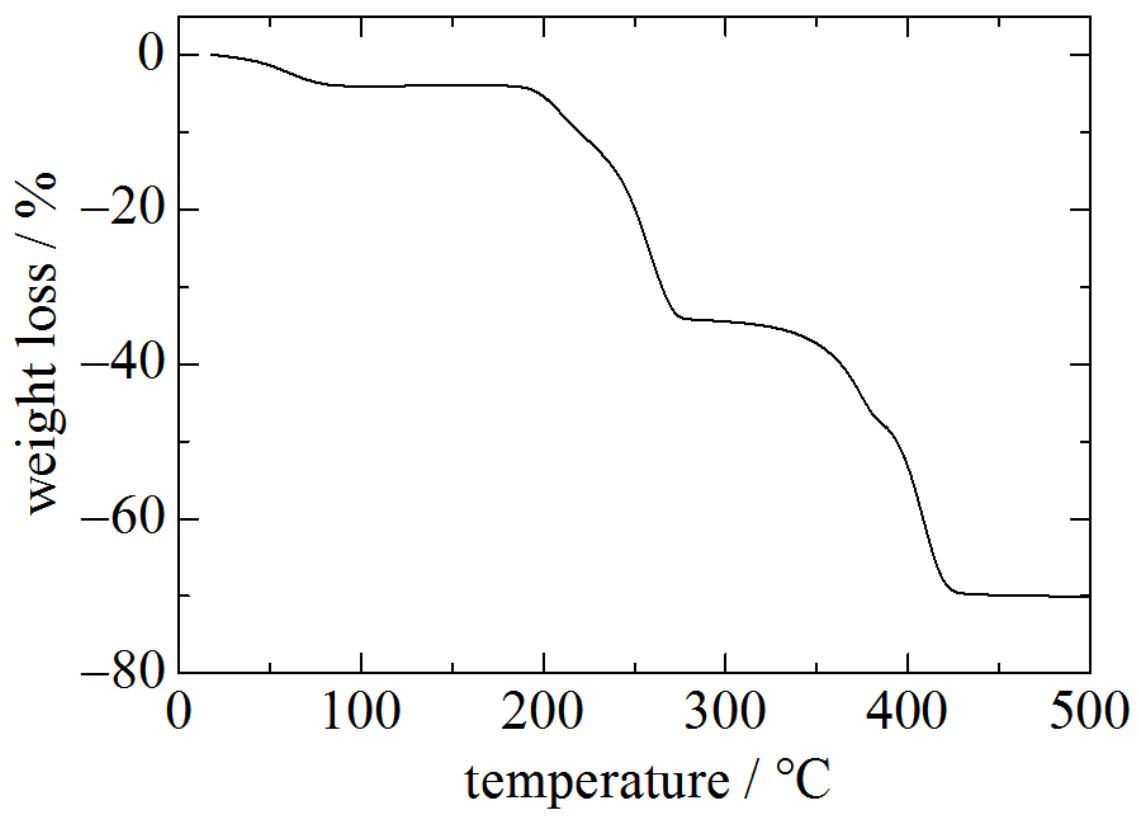

Fig. S2 Thermogravimetry of $\left(\mathrm{C}_{5} \mathrm{H}_{6} \mathrm{~N}\right)_{2}\left[\mathrm{Zn}_{2}(\mathrm{ox})_{3}\right] \cdot 1.5 \mathrm{H}_{2} \mathrm{O}$. 


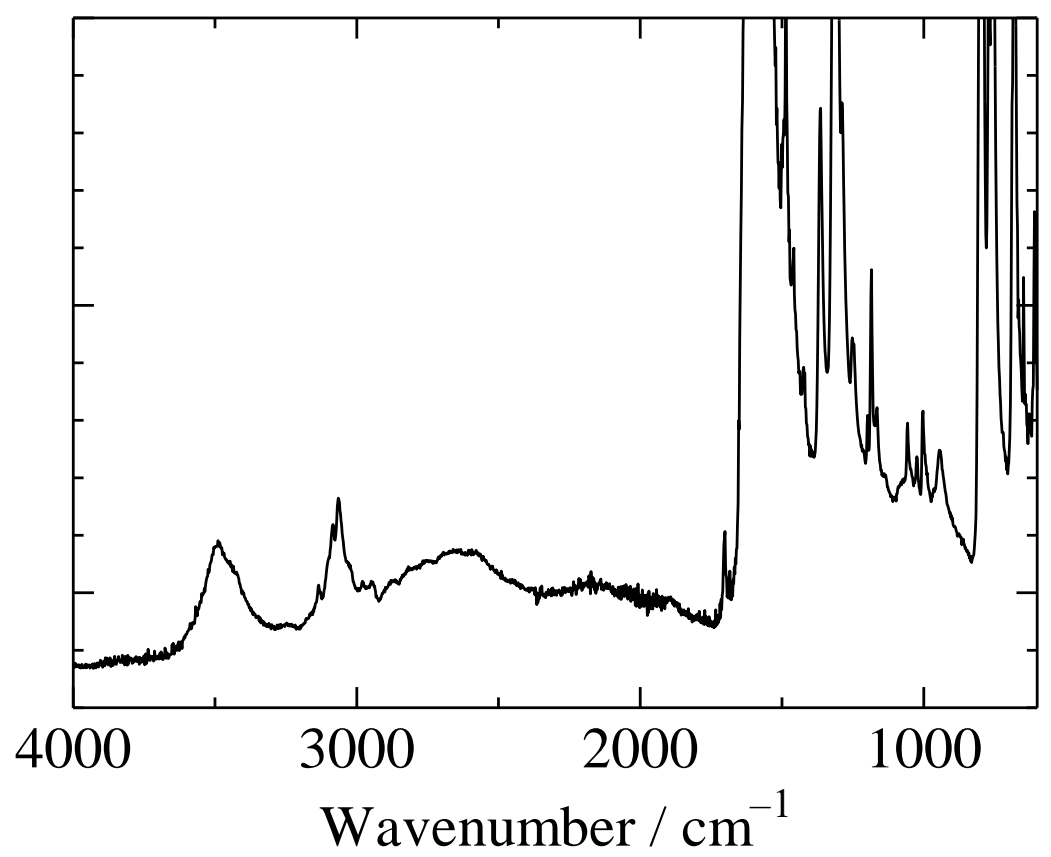

Fig. S3 IR spectrum of $\mathbf{1} \cdot n \mathrm{H}_{2} \mathrm{O}$.

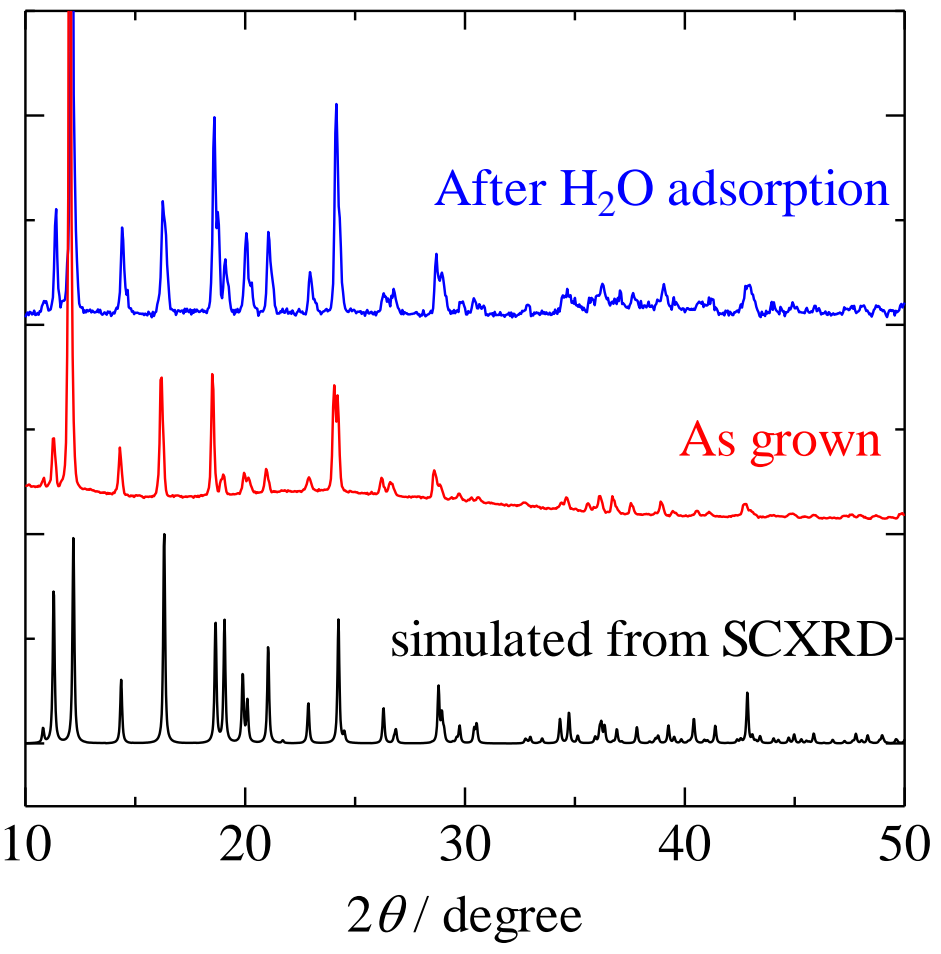

Fig. S4 Powder XRD patterns of as grown sample, powder after $\mathrm{H}_{2} \mathrm{O}$ adsorption measurement and simulated from single crystal. 

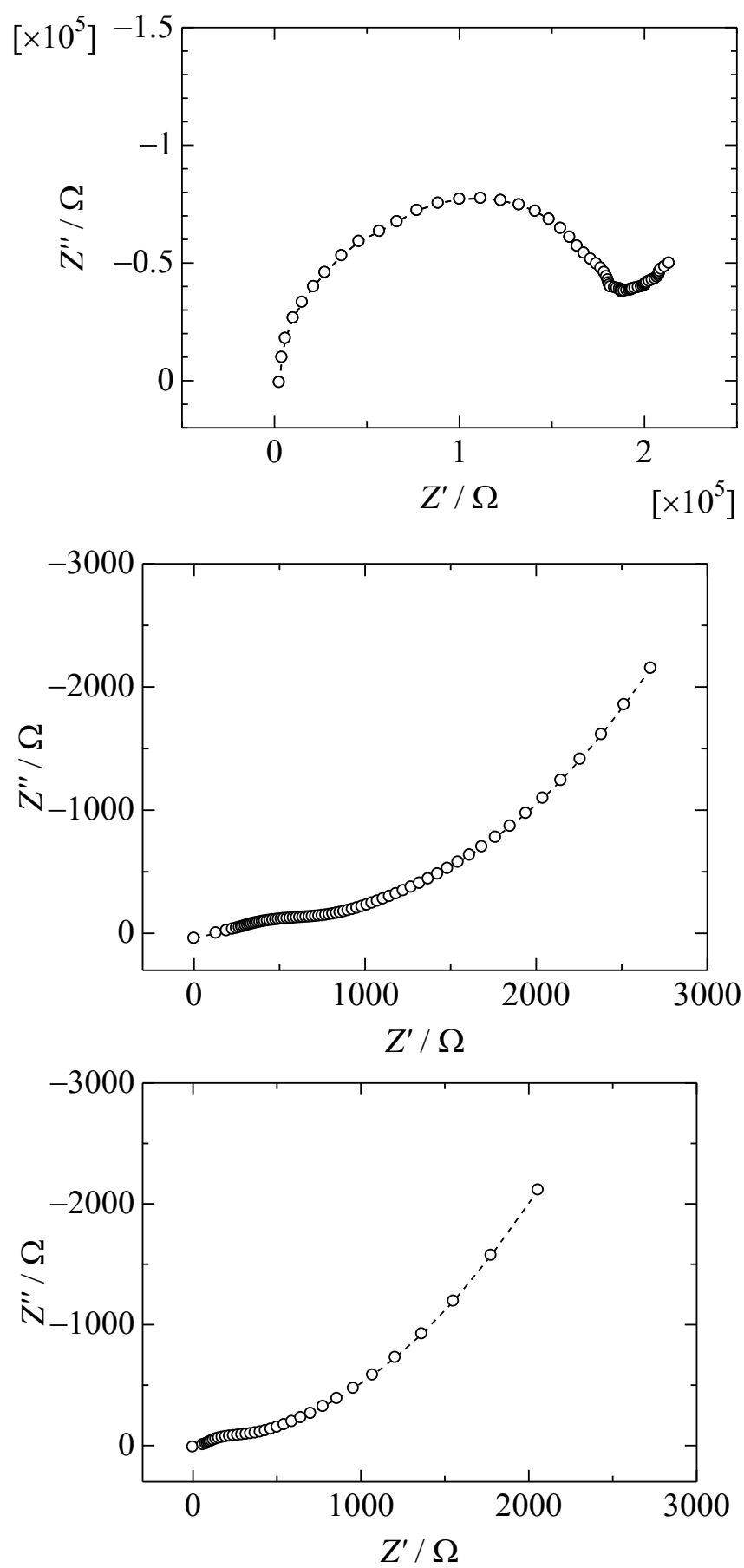

Fig. S5. Nyquist plots of $1 \cdot \mathrm{nH}_{2} \mathrm{O}$ at $298 \mathrm{~K}$ and at (top) $90 \% \mathrm{RH}$, (middle) $95 \% \mathrm{RH}$ and (bottom) $98 \% \mathrm{RH}$. 